\title{
ANÁLISE CRÍTICA DAS NORMAS E DEFEITOS DECORRENTES DA SOLDAGEM ALUMINOTÉRMICA*
}

Alessandra Regina Machado Schifino ${ }^{1}$ Afonso Reguly²

\section{Resumo}

Neste trabalho foi realizado um estudo comparativo entre as normas utilizadas para validação da solda aluminotérmica em trilhos do tipo Premium - Vignole dos modelos TR, utilizada em reparos de trilhos ferroviários. As normas a serem comparadas são: ABNT (Associação Brasileira de Normas Técnicas), AREMA (American Rail Way Engineering and Maintenance of Way Association) e a Norma Europeia (British Standard - Railway Aplication Track Auminothermic Welding of Rails). Esta comparação será realizada para avaliar a relevância da variação dos parâmetros utilizados em cada uma das normas e quais fatores devem ser analisados em mais de uma norma para que não haja dúvidas se os trilhos estão aptos para serem colocados em operação. Através da realização dos ensaios mecânicos e metalúrgicos, sugeridos pelas normas, encontra-se defeitos causados por diversos fatores, tais como: processo de fabricação, mau uso dos trilhos, falhas operacionais na soldagem, de preenchimento, de solidificação entre outros. Utilizando-se deste conjunto de informações será possível validar as soldas aluminotérmicas testadas.

Palavras-chave: Soldagem aluminotérmica; Defeitos de soldagem aluminotérmica; Normas de soldagem aluminitotérmica; Validação de solda aluminotérmica.

\section{CRITICAL ANALYSIS OF STANDARDS AND DEFECTS ARISING FROM ALUMINOTHERMIC WELDING}

\section{Abstract}

In this work, it was carried out a comparative study between standards used for validation of aluminothermic welding on Premium - Vignole rails of TR models, used on rail repairs. The standards to be compared are ABNT (Brazilian Association of Technical Standards), AREMA (American Rail Way Engineering and Maintenance of Way Association) and European Standard (British Standard - Railway Application Track - Auminothermic Welding of Rails). The comparison will be performed to evaluate the relevance in variation of the parameters used in each standard and what factors should be analyzed in more than one standard, so there is no doubt if the rails are fit to be put into operation. Through the performance of mechanical and metallurgical tests, suggested by the standards themselves, we find I defects $d$ mechanical properties, caused by several factors, such as: manufacturing process, rail misuse, operational failures in welding, filling, solidification among others. Using this set of information, it will be possible to validate the aluminothermic welds tested.

Keywords: Aluminothermic weldin; Aluminothermic welding defects; Aluminothermic welding standard; Aluminothermic welding validation.

1 Engenharia Metalúrgica, Mestranda, Laboratório de Metalurgia Física (LAMEF) PPGE3M/UFRGS, Universidade Federal do Rio Grande do Sul, Porto Alegre, RS, Brasil.

2 Engenheiro Metalúrgico, Prof. Dr. Afonso Reguly, Laboratório de Metalurgia Física (LAMEF) PPGE3M/UFRGS, Universidade Federal do Rio Grande do Sul, Porto Alegre, RS., Brasil. 


\section{INTRODUÇÃO}

O transporte ferroviário possui vantagens em relação a outros meios de transporte, pois permite maior capacidade de transporte de carga e de passageiros. Em países em desenvolvimento, tais como África e América Latina, foi escolhido o uso predominante das rodovias ao invés das ferrovias [1]. Dentre as ferrovias brasileiras de grande porte se pode citar a Estrada de Ferro Carajás (EFC) da Companhia Vale do Rio Doce (Vale) que faz a ligação entre a Serra do Carajás e o Terminal Ferroviário da Ponta da Madeira, totalizando 900 quilômetros de via contínua [2]. Na manutenção e preservação destas ferrovias, utiliza-se a soldagem aluminotérmica. Levando-se em conta seu curto tempo e flexibilidade de realização em campo, podendo ser executada entre as passagens dos trens. Isto tudo ocorre pela sua relativa simplicidade e principalmente independência de fontes externas de energia neste processo [3]. Existem diferentes normas, tais como ABNT (Associação Brasileira de Normas Técnicas) [4], AREMA (American Rail Way Engineering and Maintenance of Way Association) [6] e a europeia (British Standard - Railway Aplication Track - Auminothermic Welding of Rails) [5] para determinar os tipos de ensaios e quais parâmetros devem ser utilizados para identificar tais defeitos. Os trilhos que serão analisados são todos do tipo Premium - Vignole e pertencem a diferentes empresas ferroviárias. Neste trabalho através de ensaios mecânicos e metalúrgicos, de acordo com as normas já citadas, obteremos um mapa dos variados defeitos decorrentes da soldagem aluminotérmica.

\section{MATERIAIS E MÉTODOS}

O fluxograma mostrado na Figura 1 apresenta de maneira esquemática o planejamento experimental utilizado neste estudo. Com exceção da soldagem, os demais ensaios e análises foram realizados nas dependências do Laboratório de Metalurgia Física (LAMEF-UFRGS).

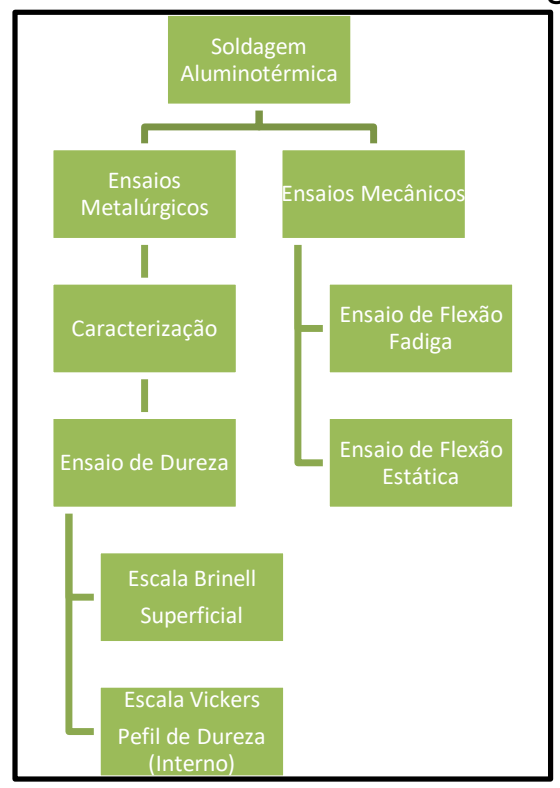

Figura 1. Fluxograma experimental utilizado neste trabalho.

Fonte: Elaborada pela autora.

Os ensaios citados acima não serão realizados em todas as amostras, pois a demanda das empresas solicitantes foi diferente. Os defeitos que trouxeram as amostras para a análise são distintos. Segue a matriz de ensaios, que nos informa que ensaios foram realizados em cada protocolo. 
Tabela 1. Matriz de Ensaios

\begin{tabular}{ccccc}
\hline $\begin{array}{c}\text { Identificação } \\
\text { do Protocolo }\end{array}$ & $\begin{array}{c}\text { Dureza } \\
\text { Brinell }\end{array}$ & $\begin{array}{c}\text { Dureza } \\
\text { Vickers }\end{array}$ & $\begin{array}{c}\text { Ensaio de } \\
\text { Fadiga }\end{array}$ & $\begin{array}{c}\text { Ensaio } \\
\text { Estático }\end{array}$ \\
\hline 01 & $\mathrm{X}$ & $\mathrm{X}$ & & \\
\hline 02 & $\mathrm{X}$ & $\mathrm{X}$ & $\mathrm{X}$ & $\mathrm{X}$ \\
\hline 03 & $\mathrm{X}$ & & $\mathrm{X}$ & $\mathrm{X}$ \\
\hline 04 & $\mathrm{X}$ & & $\mathrm{X}$ & $\mathrm{X}$ \\
\hline
\end{tabular}

Fonte: Elaborada pela autora.

\subsection{Ensaios Metalúrgicos}

\subsubsection{Dureza Brinell}

Os ensaios de dureza superficial do boleto são realizados na escala Brinell e devem ser conduzidos de acordo com a norma ABNT [4] e a norma Europeia [5] conforme o item 7.2 e o Anexo E. Ambas as normas sugerem que os ensaios sejam realizados utilizando-se esfera com diâmetro de $10 \mathrm{~mm}$, carga aplicada de $3000 \mathrm{~kg} / \mathrm{f}$ e tempo de aplicação da carga de $15 \mathrm{~s}$. A dureza deve ser medida abaixo da zona de descarbonetação $(0,5 \mathrm{~mm}$ abaixo da superfície do rolamento). A medição deve ser efetuada conforme Figura 2. Três valores de dureza devem ser determinados para cada solda, sendo considerada como a dureza real a média das três leituras, os valores podem ser visualizados na Tabela 2. Tais valores se aplicam para as duas normas [4] e [5].

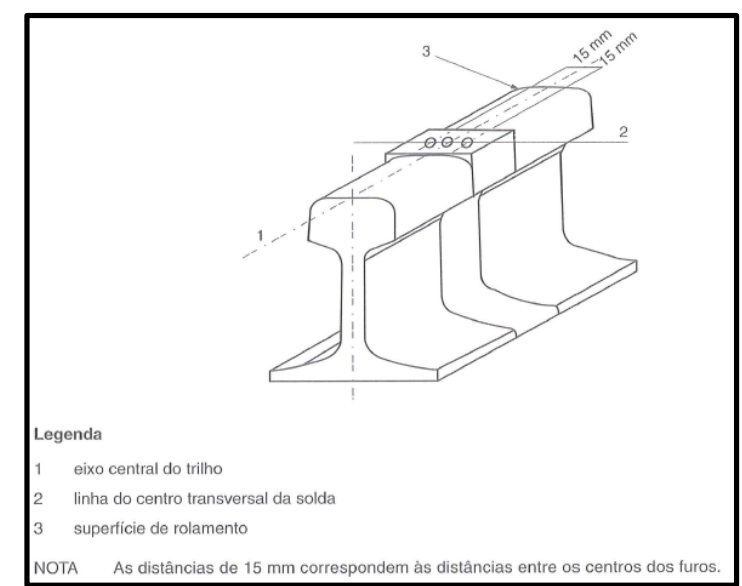

Figura 2. Diagrama de medição de dureza Brinell. Fontes: [4] e [5].

Tabela 2. Tabela comparativa de valores de dureza Brinell

\begin{tabular}{cccc}
\hline \multicolumn{2}{c}{ ABNT/Europeia (BS) } & \multicolumn{2}{c}{ AREMA } \\
\hline $\begin{array}{c}\text { Dureza da } \\
\text { Superfície do } \\
\text { Rolamento do } \\
\text { Trilho (HB) }\end{array}$ & $\begin{array}{c}\text { Dureza } \\
\text { central da } \\
\text { Solda } \\
\text { (HB) }\end{array}$ & $\begin{array}{c}\text { Dureza } \\
\text { Superficial (HB) }\end{array}$ & $\begin{array}{c}\text { Dureza Superficial } \\
\text { Máxima do Boleto } \\
\text { (HB) }\end{array}$ \\
\hline 200 a 240 & $230 \pm 20$ & 370 & 410 \\
\hline 220 a 260 & $250 \pm 20$ & - & - \\
\hline 260 a 300 & $280 \pm 20$ & - & - \\
\hline 260 a 300 & $300 \pm 20$ & - & - \\
\hline 260 a 300 & $280 \pm 20$ & - & - \\
\hline 320 a 360 & $330 \pm 20$ & - & - \\
\hline 350 a 390 350 a 390 & $350 \pm 20$ & - & - \\
\hline $350 \pm 20$ & - & \\
\hline
\end{tabular}


Fontes: [4], [5] e [6].

O duromêtro utilizado é o Durômetro Universal da marca Wolpert, modelo Die Testor 2 Rc, faixas de 400,0 a 500,0 HB (Brinell), como apresentado na Figura 3.

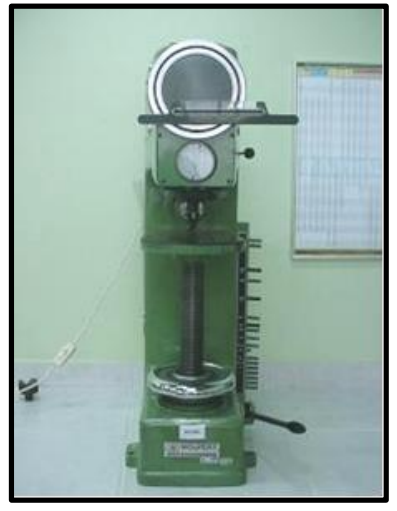

Figura 3. Durômetro universal da marca Wolpert para medições na escala Brinell.

Fonte: Elaborada pela autora.

\subsubsection{ENSAIO DE DUREZA VICKERS}

Nos casos onde for necessário realizar um perfil de dureza, a medição de dureza será efetuada seguindo o Anexo $\mathrm{J}$ da norma européia [4], nesta é citado que a distribuição da dureza na zona afetada pelo calor deve ser medida utilizando a escala Vickers e uma carga de $30 \mathrm{~kg}$. As impressões devem estar posicionadas em uma linha situada entre 3 e $5 \mathrm{~mm}$ abaixo da superfície longitudinal do boleto. A dureza na direção transversal deve estendersse para ambos os lados da solda, continuando até $20 \mathrm{~mm}$ da zona não afetada do metal base. A medição deve ser realizada até os pontos distantes $2 \mathrm{~mm}$ como mostrado na Figura 4 . As demais normas seguem os mesmo parâmetros.

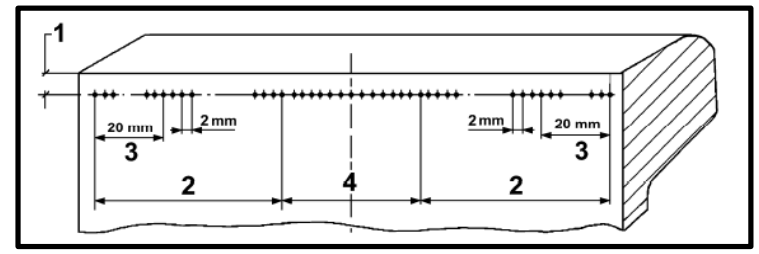

Figura 4. 1) Região de 3 a $5 \mathrm{~mm}$ abaixo da superfície longitudinal do boleto; 2) Região do metal base (zona não afetada); 3) Representação das 10 medidas com espaçamentos de $2 \mathrm{~mm}$ entre elas;

4) Região da Zona de Fusão.

Fonte: [5].

A dureza média do boleto na região do metal base em ambos os lados da solda é calculada a partir de um mínimo de dez medidas realizadas em intervalos de $2 \mathrm{~mm}$ na região. Como podese observar na Figura 4, região 3. Uma linha igual com os valores medidos de dureza média é marcada no gráfico para cada lado da solda como mostrado (linha 1). A linha de dureza de medição (linha 2) é marcada paralelamente à linha de dureza média e a distância dos pontos de dureza $X$ se encontra entre as linhas 1 e 2 . A variação da zona afetada pelo calor é definida pela distância entre os pontos A e B na Figura 5. 


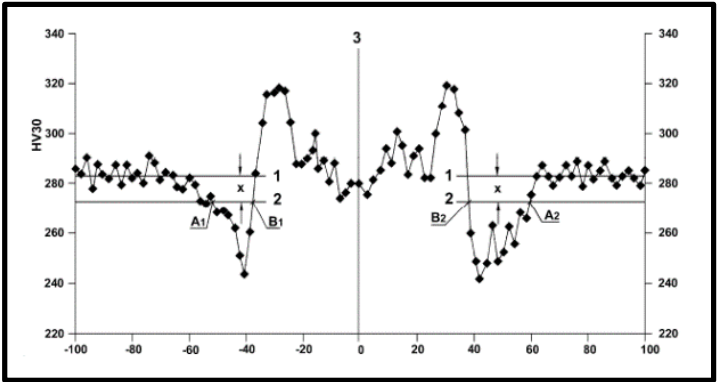

Figura 5. Perfil de dureza típico

Fonte: [5].

O microdurômetro utilizado é da marca Instron, modelo Tukson 2100 na escala HV com carga de $300 \mathrm{~g}$ de acordo com a Figura 7.

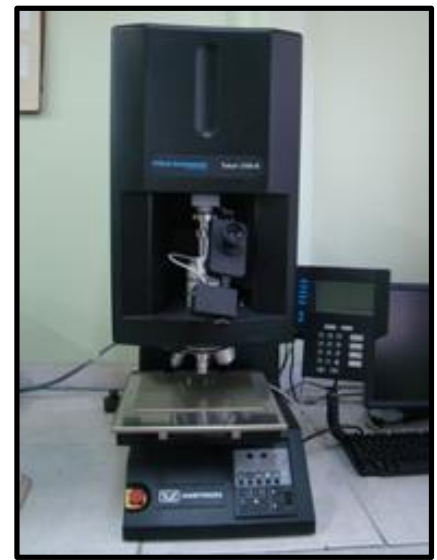

Figura 6. Microdurômetro marca Instron na escala HV com carga de $300 \mathrm{~g}$.

\subsection{ENSAIOS MECÂNICOS}

Fonte: Elaborada pela autora.

\subsubsection{Ensaio Flexão Fadiga}

Segundo a norma europeia [5] no item 7.4.3 e no Anexo K os ensaios devem ser realizados em quatro pontos de flexão com o apoio em tensão. Como na Figura 7.

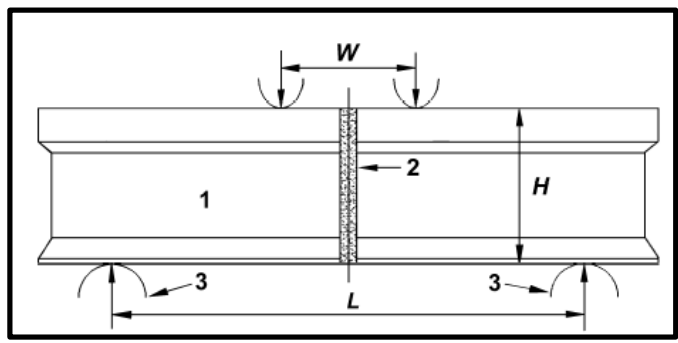

Figura 7. Arranjo para o Ensaio de Flexão Fadiga.1) Trilho; 2) Solda; 3) Apoios.

Fonte: [5].

Caso a amostra frature na região da solda durante o ensaio tendo realizado menos de 5 milhões de ciclos, o resultado não é considerado e para o caso de não haver fratura, a solda deve ser submetida a flexão até a ruptura para examinar a face de fratura quanto a região de início da falha. Se a fadiga tiver sido iniciada por falta de defeito de fusão, o processo será rejeitado. Segundo a Norma ABNT [4] para tal ensaio é necessário um atuador com dispositivo, como na Figura 8. Deve-se submeter o trilho a um carregamento cíclico, até completar 2 milhões de 
ciclos. A frequência utilizada é de normalmente 300 ciclos por minuto. A carga mínima e máxima a ser fornecida pelo atuador é calculada pelas equações:

$$
\begin{aligned}
& \mathrm{P} \min =(\sigma \min \cdot 4 \mathrm{Wx}) /(\mathrm{L}-\mathrm{L} 0) . \\
& \mathrm{P} \max =(\sigma)
\end{aligned}
$$

Onde $\sigma \min =50 \mathrm{MPa}, \sigma \max =230 \mathrm{MPa}, \mathrm{Wx}=$ módulo resultante do trilho $\left(\mathrm{mm}^{3}\right)$, $\mathrm{L}=$ distância entre os apoios ( $\mathrm{mm}$ ) e Lo = distância entre os cutelos ( $\mathrm{mm}$ ).

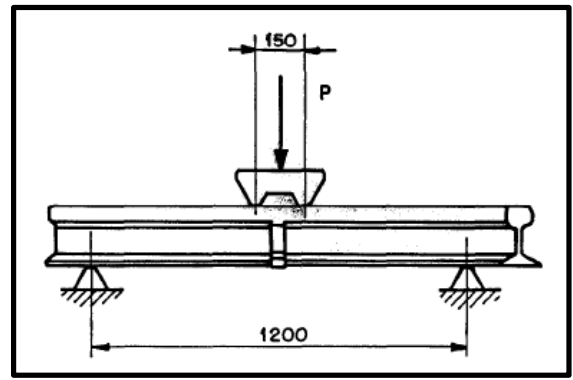

Figura 8. Disposição do Trilho no Ensaio de Fadiga. P) Carga aplicada.

Fonte: [4].

Ambas as normas seguem os parâmetros citados na Tabela 4.

Tabela 4. Tabela comparativa de parâmetros de ensaio de fadiga

\begin{tabular}{ccc}
\hline Parâmetro & Norma Europeia (BS) & Norma ABNT \\
\hline Carga Máxima & $500 \mathrm{kN}$ & $50 \mathrm{MPa}$ \\
\hline Carga Mínima & $1000 \mathrm{kN}$ & $230 \mathrm{MPa}$ \\
\hline Frequência & $5 \mathrm{~Hz}$ & $300 \mathrm{ciclos}$ \\
\hline W (distância entre os cutelos) & $150 \mathrm{~mm}$ & $150 \mathrm{~mm}$ \\
\hline L (distância entre apoios) & $1.200 \mathrm{~mm}$ & $1.200 \mathrm{~mm}$ \\
\hline Raio dos apoios e cutelos (min) & $40 \mathrm{~mm}$ & $20 \mathrm{~mm}$ \\
\hline
\end{tabular}

Fontes: [4] e [5].

Na norma AREMA [6] não existe especificações para este tipo de ensaio.

Os equipamentos utilizados nos ensaios se encontram representados na Figura 9.
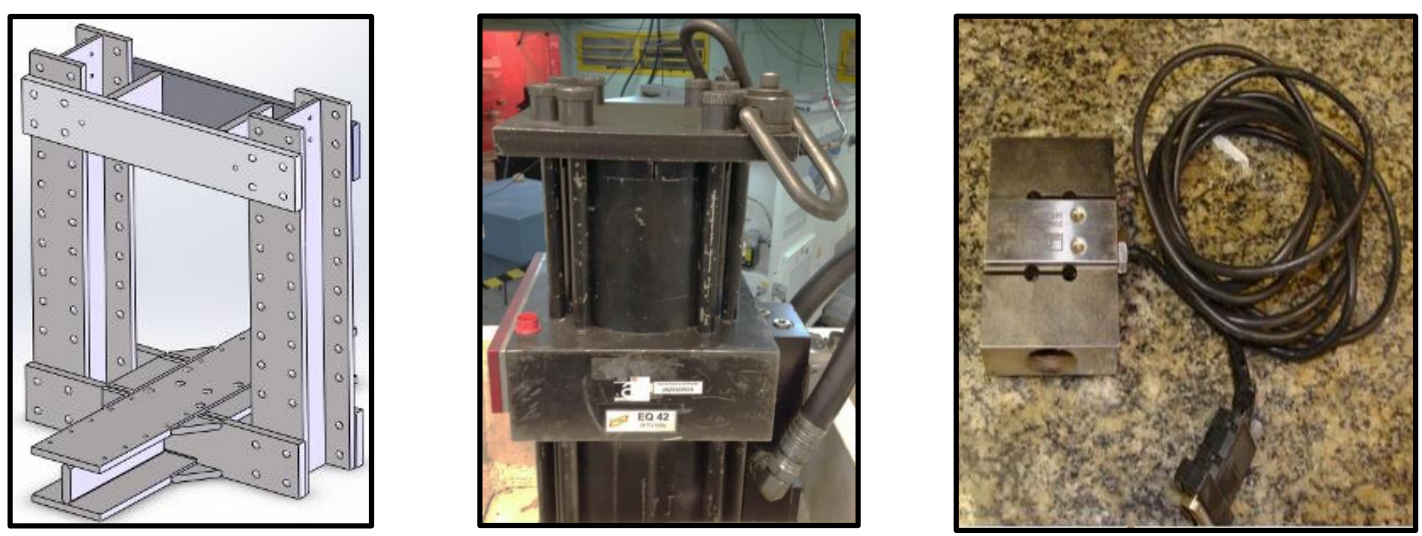

Figura 9. a) Desenho do quadro da bancada utilizada no ensaio de flexão fadiga possui $2000 \mathrm{~mm}$ de altura por 1600 $\mathrm{mm}$ de comprimento, suportando amostras de até $2000 \mathrm{~mm}$ por $700 \mathrm{~mm}$. A capacidade da carga em fadiga é de $500 \mathrm{kN}$, b) Atuador Hidráulico da marca MTS, modelo 244.41 com capacidade de carga em fadiga de $500 \mathrm{kN}$. c) Célula de carga utilizada é da marca HBM modelo S40 com capacidade de 5 toneladas.

Fonte: Elaborado pelo LAMEF. 


\subsubsection{Ensaio de Flexão Estático}

A norma AREMA [5] indica no item 3.14.4.7 e retorna ao item 3.11.3.6 que os ensaios de flexão estática devem ser realizados de acordo com a Figura 10. Um suporte externo deve ser capaz de compensar qualquer desalinhamento na base.

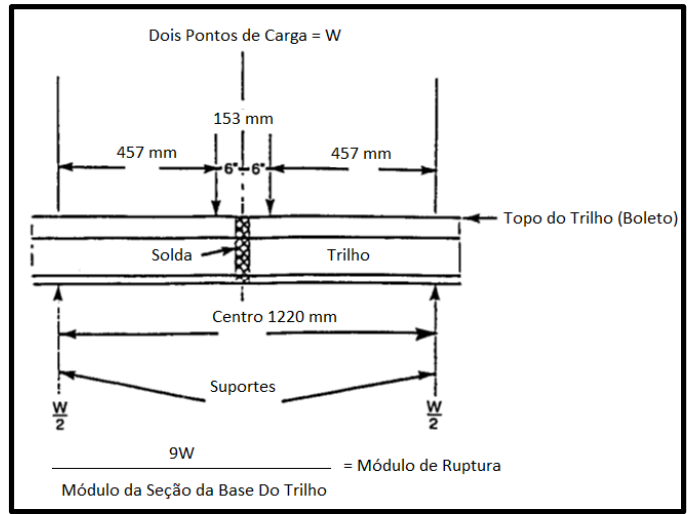

Figura 10. Arranjo de Carga para o Teste de Flexão Estático. W) Carga Fonte: [6].

A norma europeia [5] determina no item 7.3 que a carga mínima de fratura (kN) seja arredondada para o mais próximo possível de $5 \mathrm{kN}$, esse valor é definido pela equação 4 (Equivalente a uma resistência mínima à flexão à tração de $800 \mathrm{MPa}$ ), em que $\mathrm{S}\left(\mathrm{mm}^{3}\right)$ é a secção da base do trilho.

$$
\mathrm{F}=0,032 \cdot \mathrm{S}(4)
$$

Os itens abaixo devem ser respeitados: $25 \mathrm{~mm} \leq \mathrm{r} \geq 70 \mathrm{~mm}$; $\mathrm{L}=$ Comprimento mínimo da amostra $=1150 \mathrm{~mm}$, Taxa de carregamento $\leq 60 \mathrm{kN} / \mathrm{s}$.

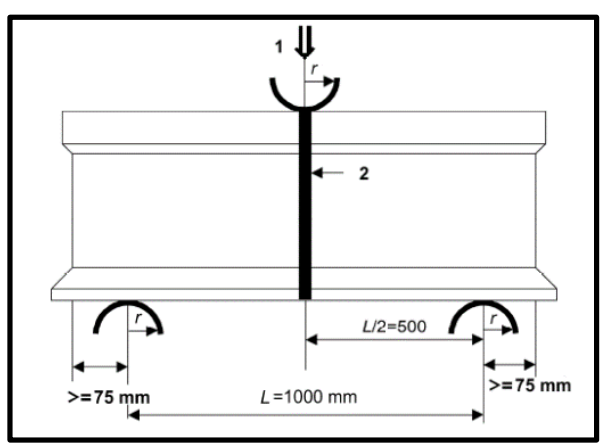

Figura 11. Arranjo de Carga para o Ensaio de Flexão Estático. 1) Carga. 2) Solda.

Fonte: [5].

A norma ABNT [4] indica no item 16 que no ensaio de flexão estático o trilho soldado deve ser realizado com carga crescente no centro da solda até a ruptura. O macho da prensa deve incidir sobre o boleto no local da solda equidistante dos apoios. Os pontos de apoio devem possuir forma cilíndrica com diâmetro de $30 \mathrm{~mm}$ a $50 \mathrm{~mm}$, e a distância entre eles deve ser de 1.000 $\mathrm{mm}$. O corpo de prova deve ter comprimento aproximado de $1.400 \mathrm{~mm}$ à temperatura ambiante. Como na Figura 12.

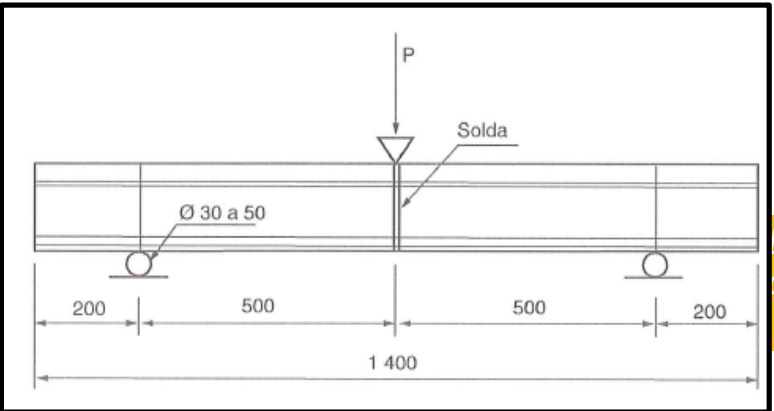


Figura 12 - Arranjo de Carga para o Ensaio de Flexão Estático. P) Carga.

Fonte: [4]

Os cáculos dos valores mínimos das cargas de ruptura deve ser feito pela seguinte equação 5, onde Wx é o valor do módulo de resistencia do patim, expresso em milimetros cúbicos $\left(\mathrm{mm}^{3}\right)$. Para os tipos de trilhos especificados na ABNT NBR 7590 [7], estes valores são apresentados na Tabela 5.

$$
\mathrm{F}=0,0032 \cdot \mathrm{W} \times(5)
$$

Tabela 5. Valores Mínimos de Carga de Ruptura

\begin{tabular}{cc} 
Tipo de Trilho & $\begin{array}{c}\text { Carga de Ruptura } \\
\text { (kN) }\end{array}$ \\
\hline TR 37 & 521 \\
\hline TR 45 & 799 \\
\hline TR 50 & 933 \\
\hline TR 57 & 1.154 \\
\hline UIC 60 & 1.200 \\
\hline GB 60 & 1.244 \\
\hline TR 68 & 1.484 \\
\hline 140 RE & 1.586 \\
\hline 141 RE & 1.519 \\
\hline
\end{tabular}

Fonte: [7].

Os equipamentos utilizados estão representados nas figuras 13a, 13b e 13c.
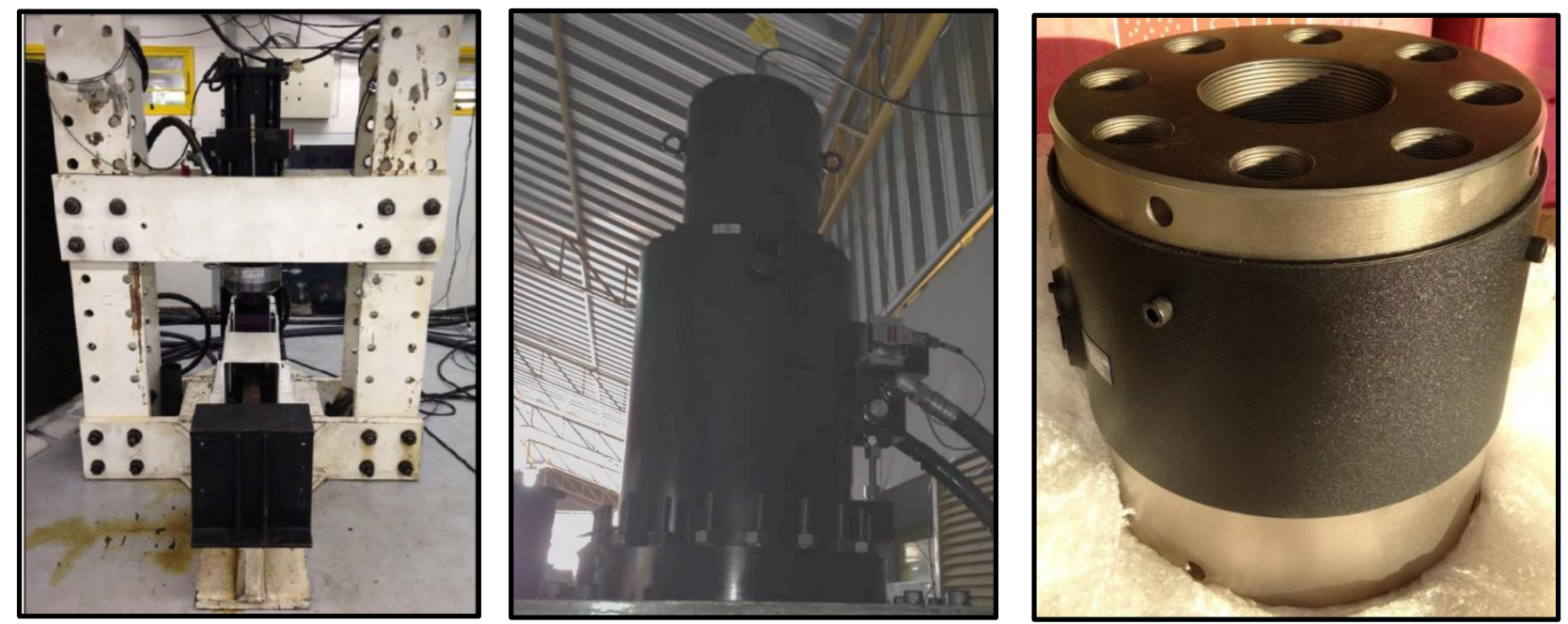

Figura 13. a) Bancada utilizada possui $1820 \mathrm{~mm}$ de altura por $2200 \mathrm{~mm}$ de largura. A capacidade de carga é de $1300 \mathrm{kN}$. b) Atuador Hidráulico da marca Hidrausul, com capacidade de carga em fadiga de $1000 \mathrm{kN}$ em tração e 1600 kN em compressão c) Célula de carga utilizada é da marca KRATUS com capacidade de $3000 \mathrm{kN}$. Fonte: Elaborada pelo LAMEF.

\section{RESULTADOS E DISCUSSÃO}




\subsection{Ensaios Metalúrgicos}

\subsubsection{Ensaio de Dureza Brinell}

A Tabela 6 representa a medição de dureza Brinell na região da solda, foram medidas as amostras dos protocolos 01, 02, 03 e 04 e realizadas suas médias.

Tabela 6. Resultados dos ensaios de dureza Brinell na região da solda

\begin{tabular}{ccccc}
\hline Protocolo & $\begin{array}{c}\text { Dureza (HB) } \\
\text { Ponto A }\end{array}$ & $\begin{array}{c}\text { Dureza (HB) } \\
\text { Ponto B }\end{array}$ & $\begin{array}{c}\text { Dureza (HB) } \\
\text { Ponto C }\end{array}$ & Média (HB) \\
\hline 01 & 306 & 299 & 304 & 303 \\
\hline 02 & 354 & 345 & 354 & 351 \\
\hline 03 & 321 & 313 & 321 & 318 \\
\hline 07 & 321 & 313 & 313 & 316 \\
\hline
\end{tabular}

Elaborada pela autora.

Na Tabela 7 foram medidas as durezas superficiais nos boletos dos trilhos, também nos protocolos 01, 02, 03 e 04.

Tabela 7. Resultados dos ensaios de dureza Brinell na região do boleto do trilho

\begin{tabular}{ccccc}
\hline Protocolo & $\begin{array}{c}\text { Dureza (HB) } \\
\text { Ponto A }\end{array}$ & $\begin{array}{c}\text { Dureza (HB) } \\
\text { Ponto B }\end{array}$ & $\begin{array}{c}\text { Dureza (HB) } \\
\text { Ponto C }\end{array}$ & Média (HB) \\
\hline 01 & - & - & - & - \\
\hline 02 & 372 & 372 & 392 & 379 \\
\hline 03 & 313 & 313 & 313 & 313 \\
\hline 07 & 313 & 313 & 313 & 313 \\
\hline
\end{tabular}

Elaborada pela autora.

\subsubsection{Ensaio de Dureza Vickers}

Seguem os gráficos dos resultados dos ensaios de dureza Vickers nas Figuras 14a e 14b.

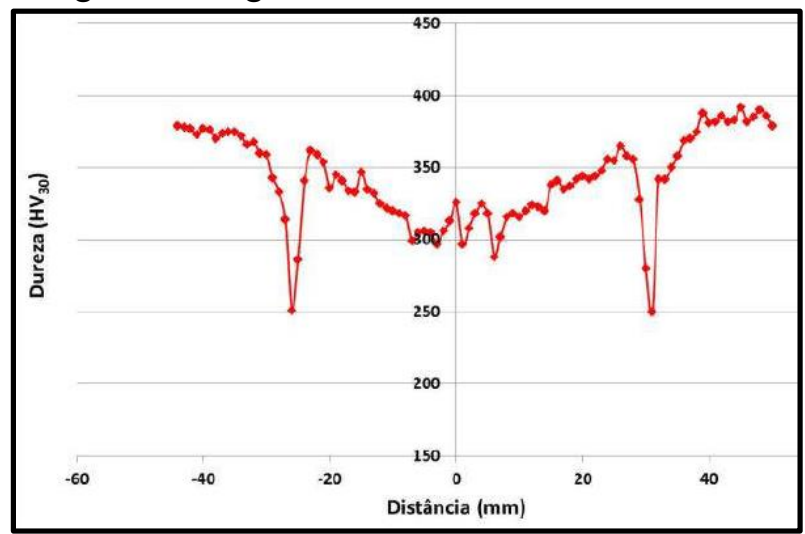

Protocolo 01. b) Perfil de Dureza na Região da

Fonte: Elaborada pela autora.

\subsection{Ensaios Mecânicos}

\subsubsection{Ensaio Flexão Fadiga}


As Figuras 15a e 15b representam a curva da força (kilonewtowns) e o deslocamento (milímetros) em função do número de ciclos na amostra do protocolo 01 e a fratura causada
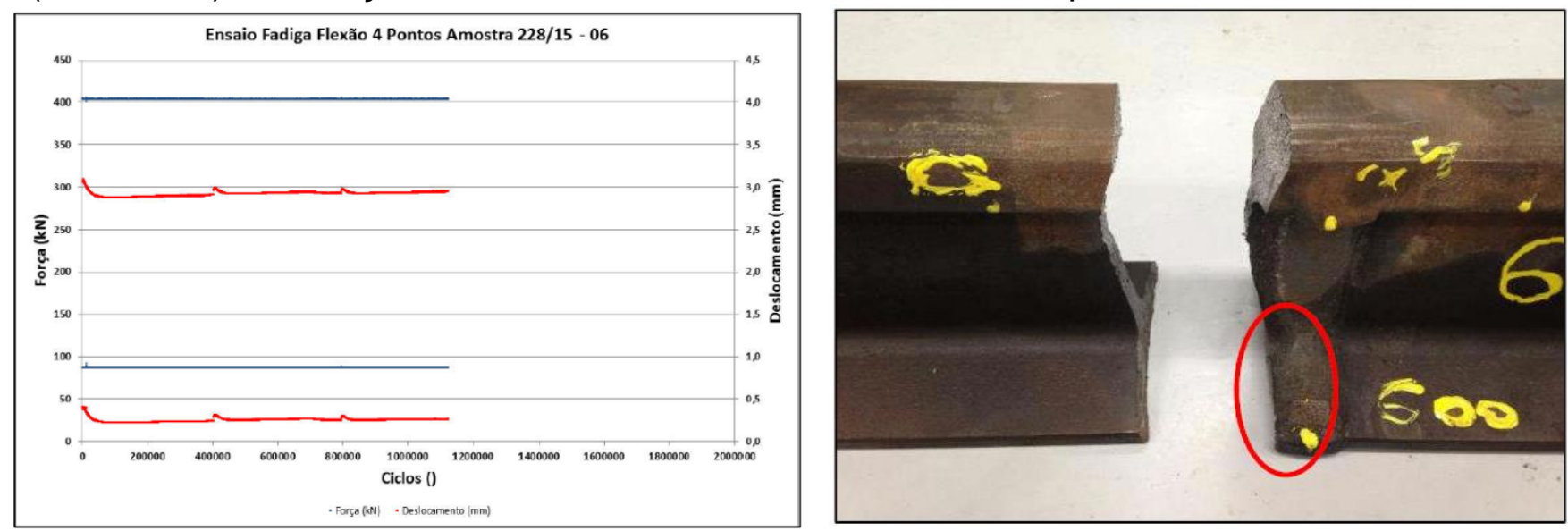

respectivamente.

Figura 15 a) Gráfico força e deslocamento em função do número de ciclos do ensaio do protocolo 02.

b) Amostra Fraturada, após ensaio de fadiga.
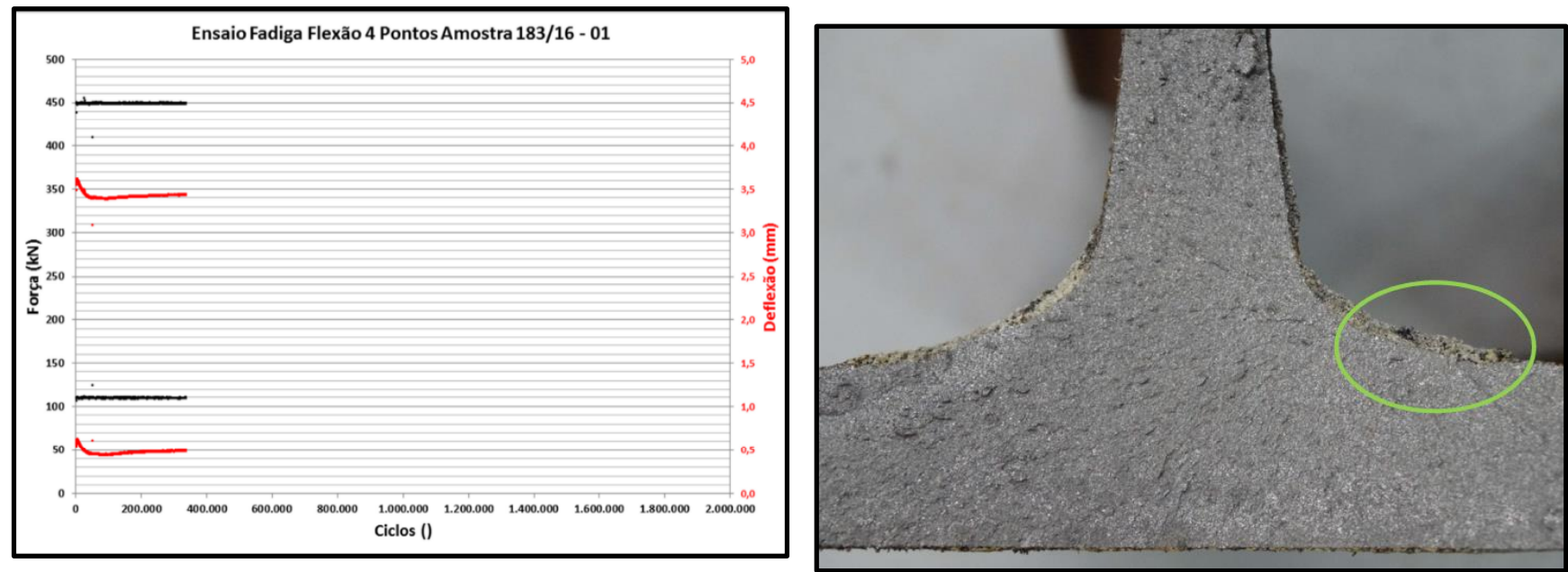

Fonte: Elaborada pela autora.

Figura 16 a) Perfil de Dureza na Região da Solda - Protocolo 03. b) Imagem das superfícies de fratura do protocolo 02. O círculo aponta o início da falha.

Fonte: Elaborada pela autora.

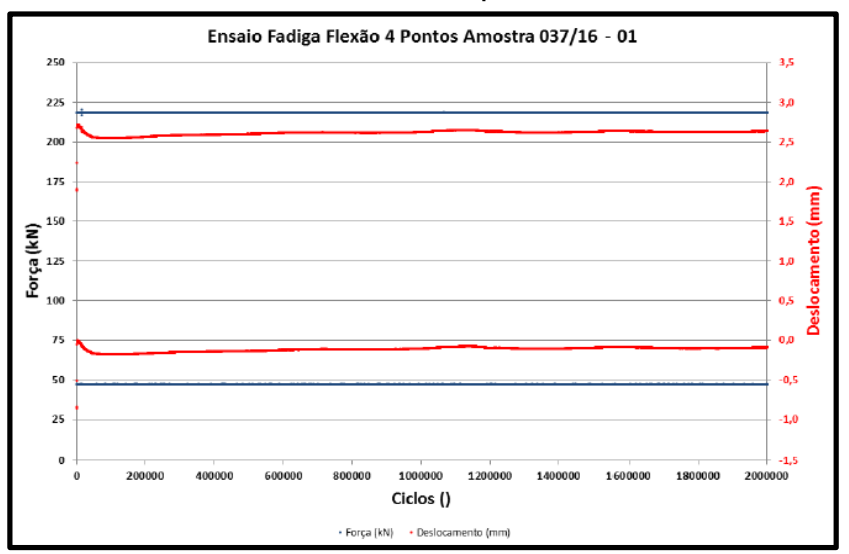

Figura 17. Amostra ensaiada do protocolo 04 atingiu os 2 milhões de ciclos nas cargas recomendadas sem romper.

Fonte: Elaborada pela autora

\subsubsection{Ensaio Flexão Estático}


As Figuras 18a, 18b e 18c representam a curva da força (kilonewtowns) e o deslocamento (milímetros) em função do número de ciclos dos protocolos ensaiados e a fratura causada respectivamente.
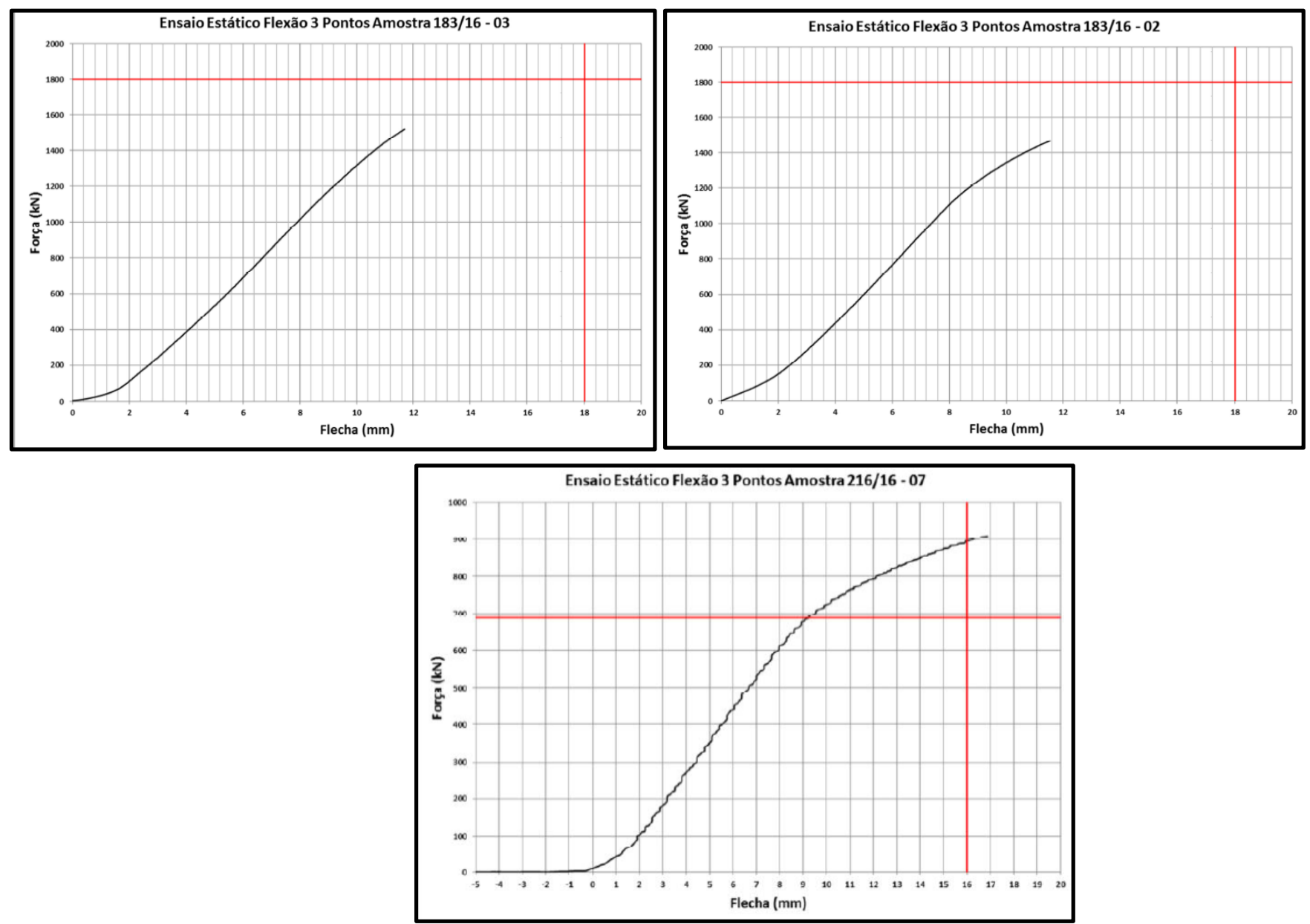

Figura 18. Gráficos em função dos deslocamentos dos ensaios de flexão estático - Protocolos 02, 03 e 04. Fonte: Elaborada pela autora.
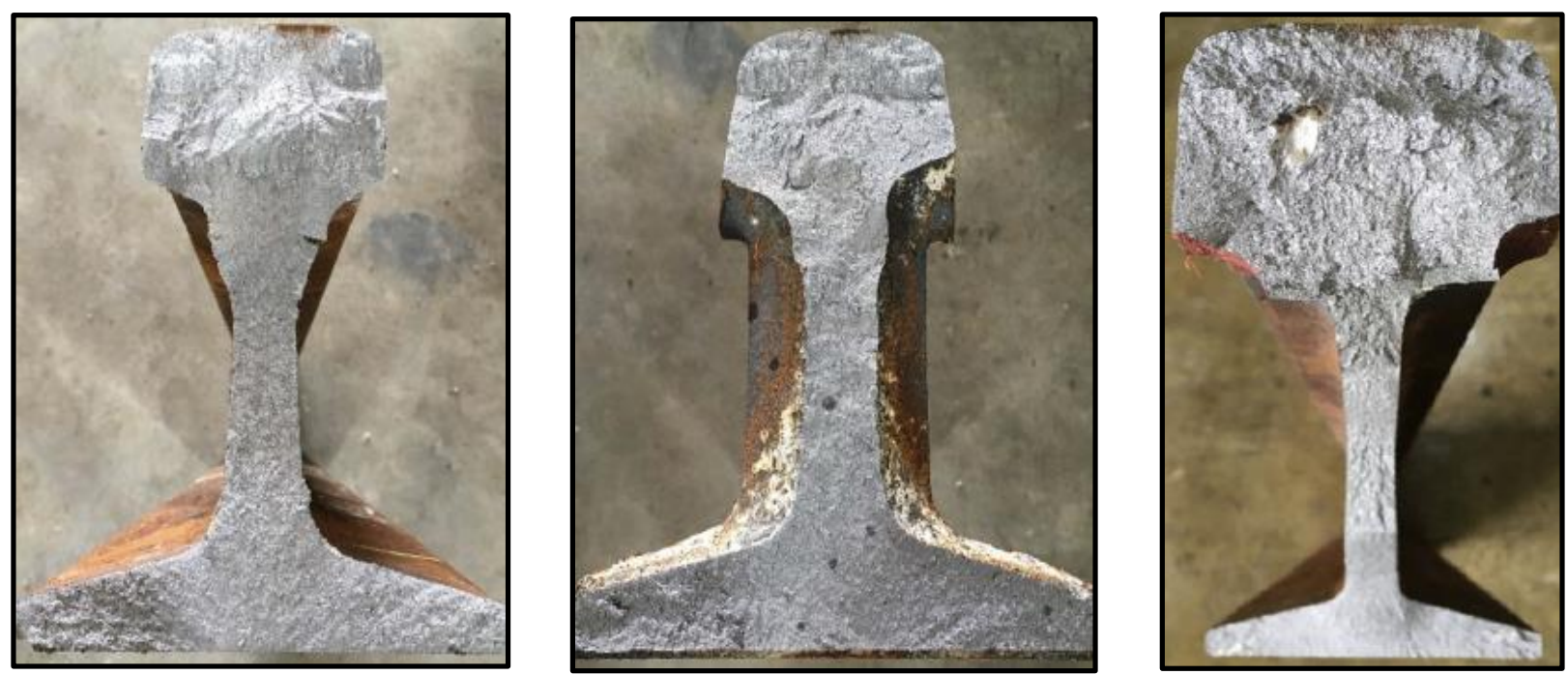

Figura 19. Imagens da superfície de fratura dos protocolos 02,03 , após o ensaio estático e o protocolo 04 , após o ensaio de flexão estático.

Fonte: Elaborada pela autora 


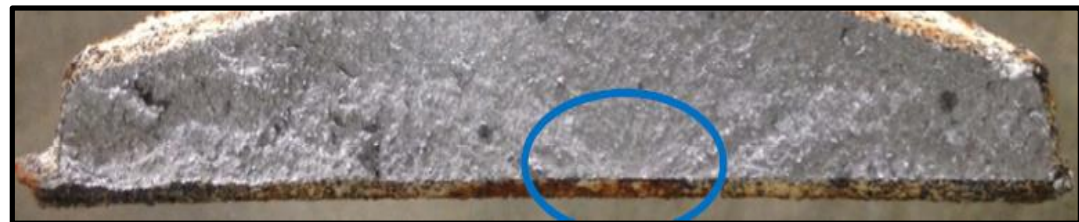

Figura 20. Imagens da superfície de fratura do protocolo 02, após o ensaio de flexão estático, possível início da falha.

Fonte: Elaborada pela autora

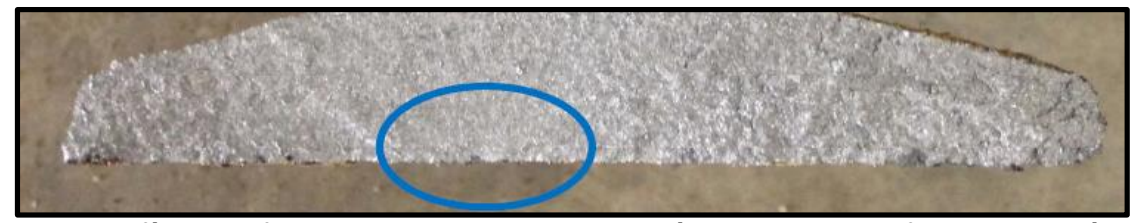

Figura 21. Imagens da superfície de fratura do protocolo 04, após o ensaio de fadiga e estático, possível início da falha.

Fonte: Elaborada pela autora

\section{CONCLUSÃO}

Os resultados da dureza Brinell, obtiveram para protocolos 01, 02, 03 e 04 respostas afirmativas de acordo com os intervalos tabelados de dureza nas normas ABNT [4] e europeia [5], variando de 299 a 351 HB. Apenas o protocolo 02 alcança a dureza de 379 HB na região do boleto, estando também de acordo com a norma AREMA [6]

Já para a dureza Vickers protocolo 01 o perfil de dureza indicou uma dureza na solda inferior ao do metal base do trilho, atingindo valores em torno de $300 \mathrm{HV}$ no centro da solda e valores de $250 \mathrm{HV}$ na zona afetada pelo calor. O metal base do trilho apresentou $380 \mathrm{HV}$. Já no protocolo 02 a dureza na solda inferior ao do metal base do trilho atingiu valores em torno de $300 \mathrm{HV}$ no centro da solda e valores de $250 \mathrm{HV}$ na zona afetada pelo calor. O metal base do trilho apresentou $400 \mathrm{HV}$, de acordo com a norma europeia [5].

Nos ensaios de flexão fadiga os protocolos 02 e 03 não estão de acordo com as normas, porém a protocolo 04 corresponde aos requisitos exigidos pelas normas ABNT [4] europeia [5] e AREMA [6] no quesito carga suportada e número de ciclos, sendo acima de 2 milhões.

Nos ensaios de flexão estática, no caso do protocolo 02 , os valores de força e a deformação (flecha) máximas atingidas nos ensaios foram de $1469 \mathrm{kN}$ e $11,54 \mathrm{~mm}$ respectivamente, no caso do protocolo 03 foram de $1521 \mathrm{kN}$ e $11,69 \mathrm{~mm}$, estando totalmente fora dos valores exigidos pelas três normas. Já no protocolo 04 a amostra foi utilizada após para realização do ensaio de flexão fadiga, pois não rompeu, obtendo carga máxima atingida de $910 \mathrm{kN}$ e a flecha máxima foi de $16,9 \mathrm{~mm}$ estando totalmente de acordo com as normas estudadas neste trabalho.

\section{REFERÊNCIAS}

1 SILVA, J. C. L. da. Breve História das Ferrovias. Brasil Escola. Disponível em: <http://brasilescola.uol.com.br/geografia/ferrovias.htm>. Acesso em: 12 dez 2010.

2 MACEDO, B. F. Estudo do Desgaste de Trilhos Ferroviários. Trabalho de conclusão de curso (Graduação). Universidade Federal de Juiz de Fora, Juiz de Fora, 2009.

3 ROSA, J. S. C. Avaliação de Solda Aluminotérmica em Ângulo. Dissertação (Mestrado). DEMET, Universidade Federal do Rio Grande do Sul, Porto Alegre, 2008.

4 ASSOCIAÇÃO BRASILEIRA DE NORMAS TÉCNICAS. ABNT NBR 15997. Trilho - Soldagem Aluminotérmica - Rail Aluminothermic Welding. 2011.

5 BRITISH STANDARDS INSTITUTION. BSI. BS EN14730-1. Railway applications -Track Aluminothermic welding of rails. London: British Standards Institution, 2006.

6 AMERICAN RAILWAY ENGENEERING AND MAINTENANCE OF WAY ASSOCIATION. AREMA, v. 1. Lanham, 2006

7 ASSOCIAÇÃO BRASILEIRA DE NORMAS TÉCNICAS. ABNT NBR 7590: Trilhos Vignole, 1991. 